\title{
An assessment of transmission efficiency on a hard disk's vibration
}

\author{
Ying-Chun Chang ${ }^{1}$, Ho-Chih Cheng ${ }^{2}$, Min-Chie Chiu ${ }^{2, *}$, and Min-Shiang Chang ${ }^{1}$ \\ ${ }^{1}$ Department of Mechanical Engineering, Tatung University, No.40, Sec. 3, Zhonshan N. Rd., Taipei \\ City 104, Taiwan, R.O.C. \\ ${ }^{2}$ Department of Mechanical and Automation Engineering, Chung Chou University of Science and \\ Technology, No. 6, Lane 2, Sec. 3, Shanjiao Rd., Yuanlin City, Changhua County 510, Taiwan, \\ R.O.C.
}

\begin{abstract}
At present, there is a trend to design a hard disk with a larger capacity, a faster revolution speed, and a precise mechanism. Therefore, the influence of data transmission with respect to vibration is obvious. To reduce interference of the vibrational impact on the data transmission efficiency, vibrational abatement on the hard disk using the damping material becomes crucial. Because of the complicated relationship for the damping coefficient and spring constant to the hardness (D1, D2, and D3) of the damping material installed under the hard disk, it is difficult to theoretically assess an optimal hardness combination of the damping material. Therefore, an alternative way by using an experimental study in conjunction with Taguchi method, an Artificial Neural Network (ANN), and a GA Method is proposed. In this paper, a hard disk is placed on a vibration tester that is an analogue to a dynamic vibrational circumstance induced by a vibrational base. The data transfer rate of the hard disk will be detected by using IOmeter software under various base-excitation accelerations, tilted angles of the hard disk, and targeted frequencies. To reduce the vibrational impact on the data transmission efficiency, an assessment of an optimal three-layer damping material installed under the hard disk using the Taguchi method, the Artificial Neural Network (ANN), and the GA Method is proposed. Before the optimization of the damping material is performed, the required experimental sets (the hardness for three layers of damping material) of the data transmission testing with respect to various design parameters will be determined by using the Taguchi method. The ANN, a simplified objective function (OBJ), will be established by inputting the hardness of three layers of damping material and their related data transmission efficiency at three targeted frequencies. Thereafter, the optimal hardness for three layers of the damping material will be obtained using a genetic algorithm (GA). Consequently, the optimal hardness of the three-layer damping material with respect to various tilted angles and target frequencies will be assessed.
\end{abstract}

*Corresponding author: minchie.chiu@msa.hinet.net 


\section{Nomenclature}

This paper is constructed on the basis of the following notations:

bit: bit length of chromosome

$\mathrm{B}_{0}, \mathrm{~B}_{\mathrm{i}}, \mathrm{B}_{\mathrm{ij}}, \mathrm{B}_{\mathrm{ijk}}$ : the coefficient of the node function in the ANN

chrm: the length of the chromosome

$\mathrm{c}_{\mathrm{i}}$ : the damping coefficient of the $\mathrm{i}$-th layer damping material $\left(\mathrm{N}-\mathrm{m} \mathrm{s}^{-1}\right)$

$c_{\text {sys }}$ : damping coefficient of vibration system $\left(\mathrm{N}-\mathrm{m} \mathrm{s}^{-1}\right)$

CPM: the product of the penalty function

$\mathrm{D}_{1}, \mathrm{D}_{2}, \mathrm{D}_{3}$ : design parameters of hardness for damping material (Shore, HS)

$f_{i 1}\left(D_{i}\right)$ : the implicit function of the damping coefficient for the i-th layer damping material with hardness of $\mathrm{D}_{1}$

$f_{i 2}\left(D_{i}\right)$ : the implicit function of the spring constant for the i-th layer damping material with hardness of $\mathrm{D}_{1}$

FSE: the deviation of mean square

$\mathrm{h}$ : the unit's number in a hidden layer

IOPS: transmission rate (Input/Output per second)

iter $_{\max }$ : maximum iteration during GA optimization

$\mathrm{k}_{\mathrm{i}}$ : the spring constant of the $\mathrm{i}$-th layer damping material

$\mathrm{k}_{\mathrm{sys}}$ : the spring constant of vibration system

$\mathrm{m}$ : mass of the hard disk $(\mathrm{kg})$

$\mathrm{M}$ : the number of the design parameters

$\mathrm{N}$ : the number of training data

$\mathrm{N}_{\mathrm{p}}$ : the total possible searching number $\left(=2^{\mathrm{M}}\right)$

pc: crossover ratio

pm: mutation ratio

pop: number of population

Q: the number of the network's coefficients

$r$ : the ration of $\omega / \omega_{n}$

$\mathrm{x}_{\mathrm{i}}, \mathrm{x}_{\mathrm{j}}, \mathrm{x}_{\mathrm{k}}$ : the input data in the ANN

$\mathrm{y}_{\mathrm{k}}$ : the output value in the ANN

$\mathrm{k}_{\mathrm{p}}$ : the penalty function in the ANN

$Y$ : input amplitude for the exciting base (m)

$\hat{y}_{i}:$ the required data in the ANN

$\mathrm{y}_{\mathrm{i}}$ : the predicted data for ANNM

$\sigma p^{2}:$ the error variation in the ANN

$\zeta$ : damping ratio of a vibration system

$\omega$ : angular velocity of the vibrational base

$\omega_{n}$ : natural angular velocity of the vibrational system

\section{Introduction}

Because of a larger capacity, a faster revolution speed, and a precise mechanism designed for a hard disk, the vibrational impact on data transmission becomes obvious. In order to reduce the influence of the data transmission on a hard disk, a vibrational control for the hard disk is necessary. Chiou and Hung (1993) simulated a floppy disk using a fixed-free circular plate rotating with a constant speed. Tsai el al. (2007) developed an active vibration-isolated system for a notebook's hard disk by modifying the connection 
between the hard disk and the primary board using both the Piezoelectric actuator and sensor within a space-constrained situation. They also verified the above vibration abatement effect by analyzing the natural frequency and the mode shape via ANASYS and an experimental test. Shiu (2008) investigated the influence of the disk's data transmission with respect to various vibrational frequencies, vibrational amplitudes and tilted angles of the disk. Because of the wide application of neural network techniques used in the parameter design during the manufacturing process (Chen, 2006; Tai, Chi, 2008), Chang (2011) advanced Shiu's study (2008) and assessed the optimization of the hardness on the damping material using the neural network in conjunction with the GA optimizer. However, only one-layer of the damping material was applied in vibration reduction. No effective experimental plan used in reducing the number of experimental tests is proposed. Therefore, in order to enhance vibration control and reduce the number of experimental tests, an assessment of the vibrational impact on the data transmission efficiency, an assessment of an optimal three-layer damping material (shown in Fig. 1) installed under the hard disk using a Taguchi method, an Artificial Neural Network (ANN), and a GA Method is proposed.

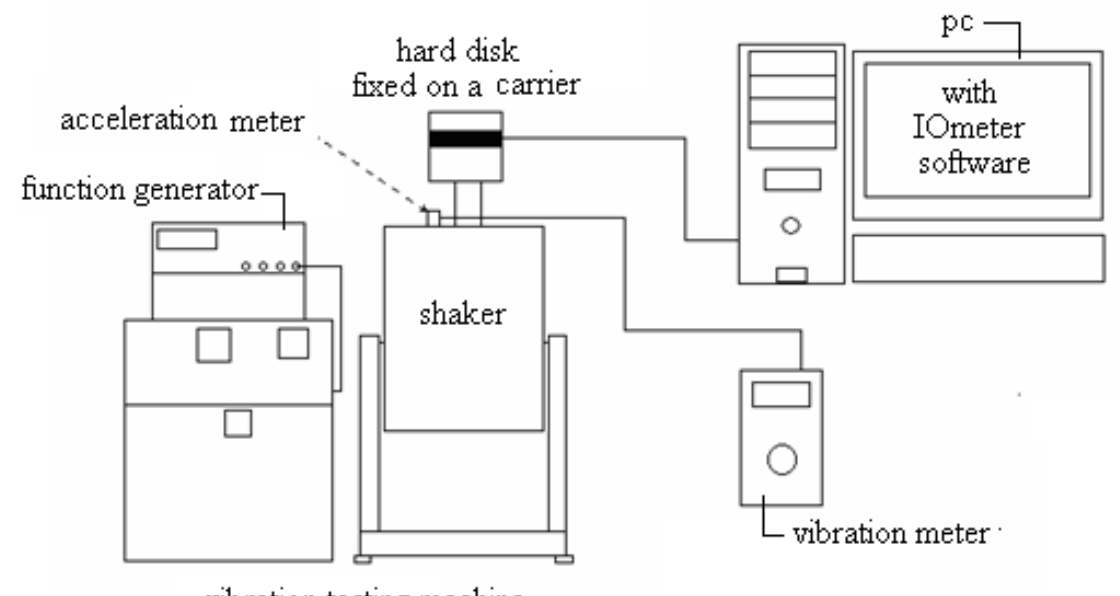

vibration testing machine

Fig. 1. The measurement of IOPS Base-excitation vibrating system for a hard disk.

\section{Mathematical model in vibration}

For a three-layer damping material installed under the hard disk with tilted angle of $0^{\circ}$, the equivalent spring/damping system is depicted in Fig.2. The related free-body diagram for a one-mass vibrational system is also shown in Fig. 3. Based on Newton's second law, the equation of motion is

$$
\begin{aligned}
& m \ddot{z}_{1}+c_{s y s}\left(\dot{z}_{1}-\dot{z}_{o}\right)+k_{s y s}\left(z_{1}-z_{o}\right)=0 \\
& \frac{1}{c_{s y s}}=\frac{1}{c_{1}}+\frac{1}{c_{2}}+\frac{1}{c_{3}} ; \quad \frac{1}{k_{s y s}}=\frac{1}{k_{1}}+\frac{1}{k_{2}}+\frac{1}{k_{3}} ; c_{1}=f_{11}\left(D_{1}\right) ; k_{1}=f_{12}\left(D_{1}\right) ; \\
& c_{2}=f_{21}\left(D_{2}\right) ; k_{2}=f_{22}\left(D_{2}\right) ; c_{3}=f_{31}\left(D_{3}\right) ; k_{3}=f_{32}\left(D_{3}\right) ;
\end{aligned}
$$

where $\mathrm{D}_{1}, \mathrm{D}_{2}$, and $\mathrm{D}_{3}$ are the hardness with respect to three kinds of damping material.

Assuming that the base is harmonically excited yields

$$
z_{o}=Y \sin (\omega \cdot t)
$$

The relative displacement $\mathrm{z}$ is set at 


$$
z=z_{1}-z_{o}
$$

Plugging Eqs.(2) and (3) into Eq. (1) yields

$$
m \ddot{z}+c_{s y s} \dot{z}+k_{s y s} z=m \omega^{2} Y \sin (\omega \cdot t)
$$

The solution to Eq. (4) is

$$
\begin{aligned}
& z(t)=Z \sin (\omega t-\phi) \\
& Z(\omega)=\frac{m Y \omega^{2}}{\sqrt{\left(k-m \omega^{2}\right)^{2}+c_{s y s}^{2} \omega^{2}}} ; \\
& =Y \frac{r^{2}}{\sqrt{\left(1-r^{2}\right)^{2}+(2 r \zeta)^{2}}} \\
& r=\frac{\omega}{\omega_{n}} ; \phi=\tan ^{-1}\left(\frac{c_{s y s} \omega}{k-m \omega^{2}}\right) ; \\
& \varsigma=\frac{c_{s y s}}{2 \sqrt{k_{s y s} m}}=\frac{\frac{c_{1} \cdot c_{2} \cdot c_{3}}{c_{1} \cdot c_{2}+c_{1} \cdot c_{3}+c_{2} \cdot c_{3}}}{2 \sqrt{\left(\frac{k_{1} \cdot k_{2} \cdot k_{3}}{k_{1} \cdot k_{2}+k_{1} \cdot k_{3}+k_{2} \cdot k_{3}}\right)}} \\
& =\frac{\frac{f_{11}\left(D_{1}\right) \cdot f_{21}\left(D_{2}\right) \cdot f_{31}\left(D_{3}\right)}{f_{11}\left(D_{1}\right) \cdot f_{21}\left(D_{2}\right)+f_{11}\left(D_{1}\right) \cdot f_{31}\left(D_{3}\right)}}{2 \sqrt{\frac{f_{21}\left(D_{2}\right) \cdot f_{31}\left(D_{3}\right)}{f_{12}\left(D_{1}\right) \cdot f_{22}\left(D_{2}\right) \cdot f_{32}\left(D_{3}\right)}}} \\
& \sqrt{\frac{f_{12}\left(D_{1}\right) \cdot f_{22}\left(D_{2}\right)+f_{12}\left(D_{1}\right) \cdot f_{32}\left(D_{3}\right)}{+f_{22}\left(D_{2}\right) \cdot f_{32}\left(D_{3}\right)}}
\end{aligned}
$$

Because the damping coefficients and spring constants with respect to three kinds of damping material are related to the implicit functions $\left(f_{11}, f_{12}, f_{21}, f_{22}, f_{31}, f_{32}\right)$ of the hardness $\left(D_{1}, D_{2}\right.$, and $\left.D_{3}\right)$, it is difficult to exactly find a best hardness combination of the three damping material. Therefore, an alternative way by using a Taguchi method, an Artificial Neural Network (ANN), and a GA Method is proposed.

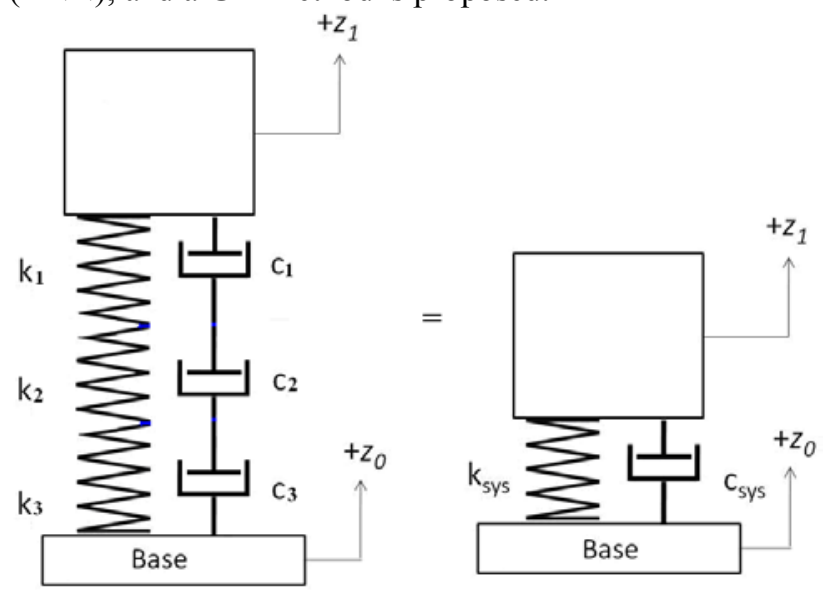

Fig. 2. The equivalent spring/damping system of IOPS base-excitation vibrating system for a hard disk (tilted angle: $0^{\circ}$ ). 


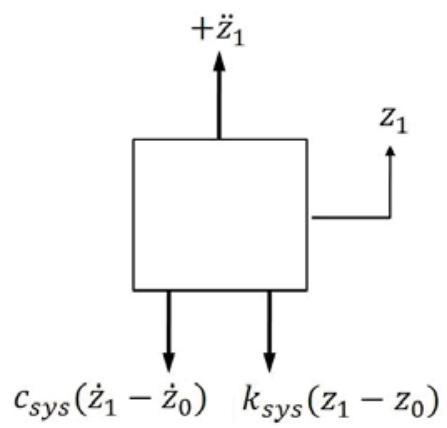

Fig. 3. The free-body diagram for a one-mass vibrational system(tilted angle: $0^{\circ}$ ).

\section{Taguchi method}

The Taguchi design is an experimental method used to improve quality by using appropriate design parameters determined by practical operations on a site or computer simulation (2000). To efficiently reduce the number of conventional experiments, the orthogonal array (Chang, 2000; Wei, 2002) using design parameters (control factors) in columns and standard (level) quantities in rows is presented. By analyzing the parameters' sensitivity to quality, the optimal parameters can be approached by the Taguchi Method (Lan, Chiu, Yeh, 2008). The steps in establishing the analysis of engineering quality using Taguchi Method include the following:

A. Selection of quality.

B. Judging the ideal functions of quality.

C. Listing all the factors that will influence quality.

D. Deciding the control factors and the related levels.

E. Selecting an appropriate orthogonal table and arranging a complete experimental plan for the control factors and the related levels.

F. Performing experimental work and recording experimental results.

G. Data analysis and comparison.

\section{Artificial neural network model (ANNM)}

Artificial Neural Networks (ANNs) have an advantage in establishing complex nonlinear relationships for complicated problems. They may be viewed as universal approximators; however the main disadvantage of this approach is that detected dependencies are hidden. To overcome this drawback, the Group Method of $n$ Data Handling (GMDH) was developed by Ivakhnenko (1971). The GMDH is a self-organized adaptive model. The interconnections between the layers of neurons are simplified, and an automatic algorithm for structure design and weight adjustment is established. Based on the GMDH's feed-forward networks and short-term polynomial transfer functions, the coefficients of the polynomial transfer functions are obtained using a regression technique. The regression technique is then combined with the emulation of the self-organizing activity for neural network (NN) structural learning. In addition, the input variable set in each layer is created. The assembled number is $p ! /[(p-\square r) ! r !]$ where $p$ is the number of input variables and $r$ is normally set to be two. As indicated in Fig. 4, the polynomial neural network is composed of an input layer, a hidden layer $-\Sigma$ (Summation), and an output layer (product) where the hidden layer is the weight summation and the output layer is the product of the input and weighted value (Patrikar, Provence, 1996). The jth output $-z_{j k}$ is 
$z_{j k}=\sum_{i=0}^{n} W_{i j} X_{i j}$

The total output of the neural network is expressed as

$$
y_{k}=\prod_{j=1}^{h} z_{j k}
$$

where $h$ is the unit's number in a hidden layer.

Combining Eqs.(4)(5) yields

$$
y_{k}=B_{0}+\sum_{i=1}^{n} B_{i} x_{i}+\sum_{i=1}^{n} \sum_{j=1}^{n} B_{i j} x_{i} x_{j}+\sum_{i=1}^{n} \sum_{j=1}^{n} \sum_{k=1}^{n} B_{i j k} x_{i} x_{j} x_{k}+\ldots \ldots \ldots \ldots \ldots
$$

where $y_{k}$ is the output value, $x_{i}, x_{j}, x_{k}$ is the input data, and $B_{0}, B_{i}, B_{i j}$, and $B_{i j k}$ are the coefficient of the node function.

To obtain the ANNM, the experimental data of the hardness (D1, D2, and D3) for three layers of damping material installed under the hard disk and the output data (IOPS) is used. The trained ANNM can be achieved using both the training data bank and the polynomial calculation in conjunction with the PSE standard (deviation of mean square).

PSE has the form

$$
\begin{aligned}
& \mathrm{PSE}=\mathrm{FSE}+\mathrm{k}_{\mathrm{p}} \\
& \mathrm{FSE}=\frac{1}{N} \sum_{i=1}^{N}\left(\hat{y}_{i}-y_{i}\right)^{2}
\end{aligned}
$$

where FSE is the deviation of the mean square, $k_{p}$ is the penalty function, $\mathrm{N}$ is the number of training data, $\hat{y}_{i}$ is the required data, and $y_{i}$ is the predicted data for the ANNM.

The penalty function $\mathrm{k}_{\mathrm{p}}$ is

$$
k_{p}=\mathrm{CPM} \frac{2 \sigma p^{2} Q}{N}
$$

where CPM is the product of the penalty function, $\sigma p^{2}$ is the error variation, and $\mathrm{Q}$ is the number of the network's coefficients. The related steps of the ANNM construction are shown in Fig. 5. The predicted IOPS can be obtained by inputting arbitrary design data. The ANNM, an OBJ function, works in conjunction with the GA optimizer during the optimization process.

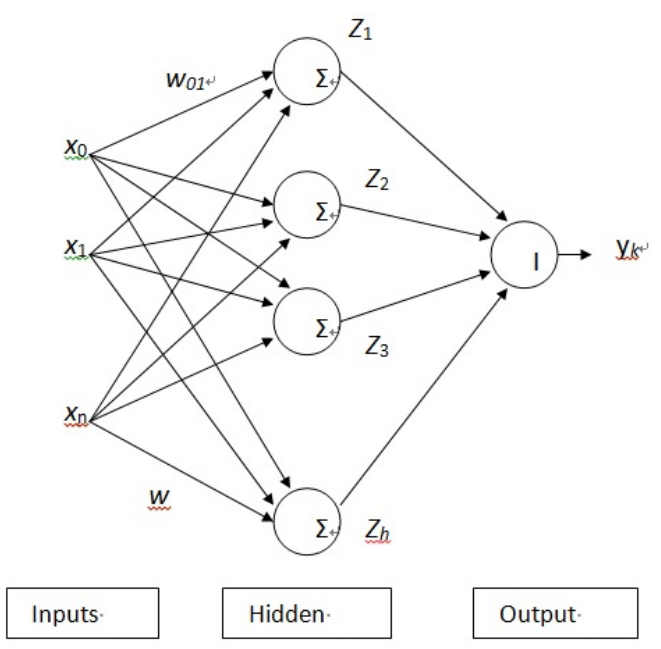

Fig. 4. Structure of the artificial neural network. 


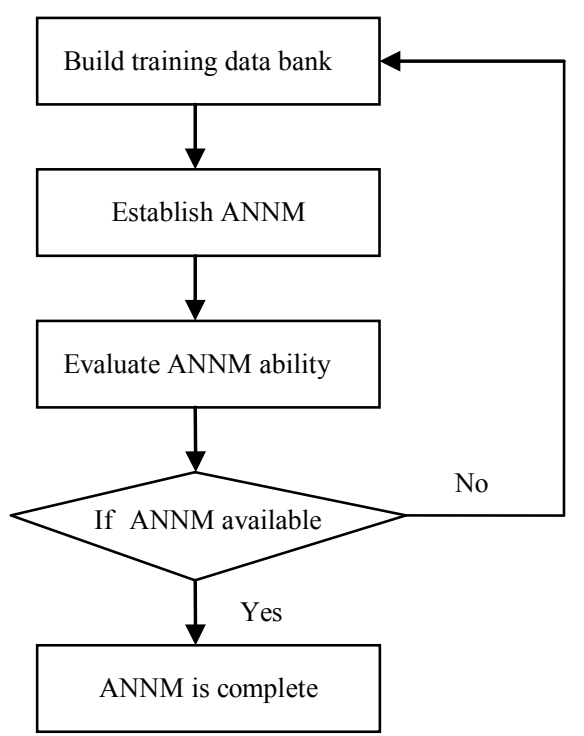

Fig. 5. The steps in the ANNM.

\section{Genetic algorithm}

The concept of Genetic Algorithms, was first formalized by Holland (1975) and later extended to functional optimization by Jong (1975). It involves the use of optimization search strategies patterned after the Darwinian notion of natural selection. For the optimization of the objective function $(O B J)$, the design parameters of $X 1, X 2, \ldots, X_{\mathrm{m}}$ were determined. Initialization is carried out by setting the population size (pop), the length of the chromosome (chrm), the crossover ratio (pm), the mutation ratio $(\mathrm{pc})$, the maximum iteration $\left(\right.$ iter $_{\max }$ ), the selection method(elitism), the parameter numbers, and the searching ranges of the parameters. Each candidate parent will be selected by the coding/decoding transformation and the fitness $(O B J)$ calculation. The precision $(\mathrm{M})$ of the parameter search is

$$
M=\frac{P_{\max }-P_{\min }}{N_{p}-1}
$$

where $N_{\mathrm{p}}\left(=2^{\mathrm{m}}\right)$ is the total possible searching number, $\mathrm{m}$ is the number of the design parameters, $\mathrm{P}_{\max }$ is the maximum range of the parameter, and $\mathrm{P}_{\min }$ is the minimum range of the parameter. The tournament selection will be adopted as the elitism mechanism in the GA optimization. In addition, the uniform crossover shown in Fig. 6 is applied in the optimization process. Moreover, as indicated in Fig. 7, the mutation scheme is also used to widen the range of the chromosome. The operations in the GA method are pictured in Fig. 8 . The process was terminated when a number of generations exceeded a pre-selected value of iter $r_{\max }$. 


\begin{tabular}{|l|l|l|l|l|l|l|l|l|l|l|l|}
\hline 1 & 0 & 1 & 0 & 0 & 1 & 0 & 1 & 1 & 0 & 1 & 0 \\
\hline & 1 & 1 & 1 & 1 & 1 & 1 & 1 & 1 \\
\hline & 1 & 1 & 1 & 0 & 0 & 1 & 1 & 0 & 1 & 1 & 1 \\
\hline
\end{tabular}

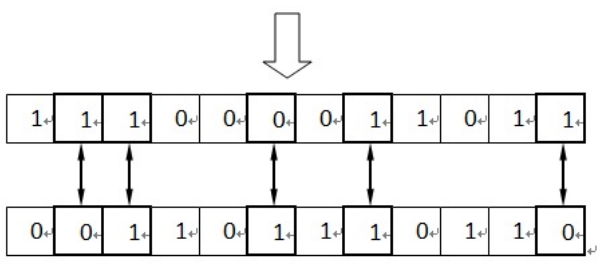

Fig. 6. Mechanism of uniform crossover.

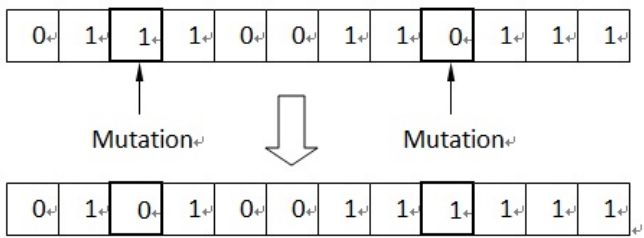

Fig. 7. Mechanism of mutation.

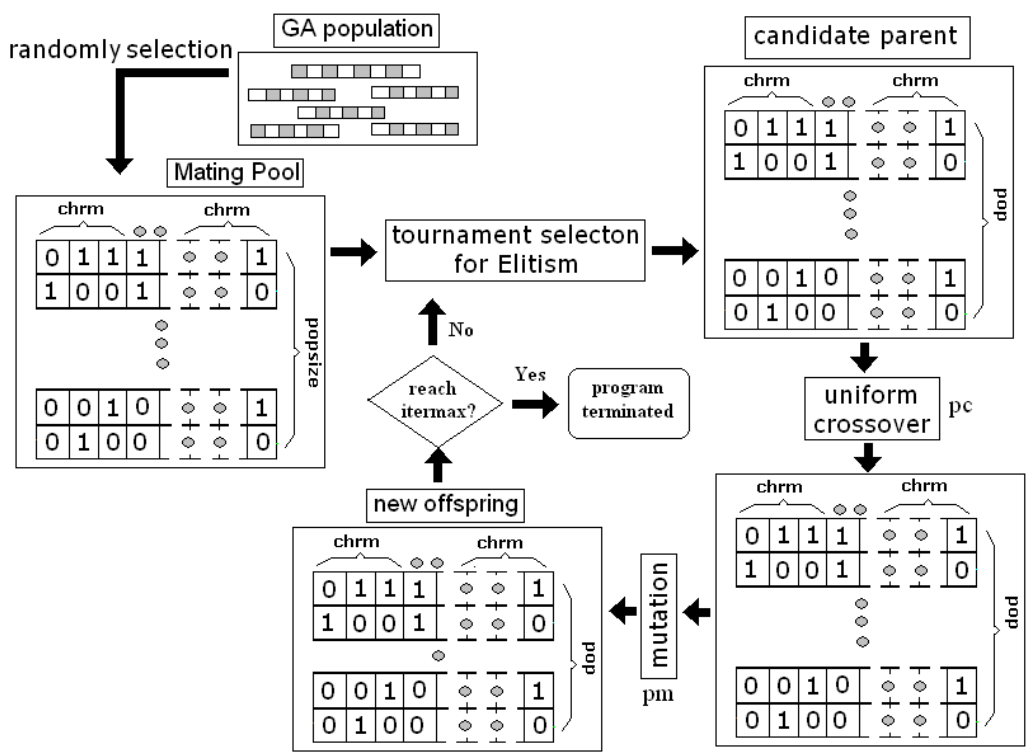

Fig. 8. The block diagram of the GA optimization on plenums.

\section{Case study}

In this paper, a three-layer damping material installed under the hard disk shown in Fig. 1 is established. An acceleration of $0.2 \mathrm{~g}$ is added in the base-excitation vibration. There are three kinds of hard disk with tilted angles $\left(0^{\circ}, 5^{\circ}\right.$, and $\left.10^{\circ}\right)$ adjusted during the experimental test. To improve the transmission efficiency of a hard disk within a base-excitation 
environment, a three-layer damping material with various combination of hardness is adopted. In addition, to realize the critical frequencies (target frequencies) that reduce the transmission efficiency of the hard disk, experimental work of an IOPS measurement at three tilted angles without damping material is carried out in advance. Thereafter, for optimal design with the highest transmission efficiency on a hard disk during the base excitation situation, three kinds of hardness $\left(D_{1}, D_{2}\right.$, and $\left.D_{3}\right)$ for three layers of damping material bundled and installed under the hard disk are chosen as the input data. The related experimental transmission rate (IOPS) serves as the output data in the ANNM. In addition, to verify the ANNM correction, training data will be inputted into the ANNM. Using the ANNM as an OBJ and adopting the GA in the optimal process, the best hardness combination of the three-layer damping material with respect to three kinds of tilted angles at the target frequency will be assessed. Moreover, in order to efficiently reduce the number of conventional experiments, the Taguchi design is introduced. The orthogonal array with respect to three tilted angles $\left(0^{\circ}, 5^{\circ}\right.$, and $\left.10^{\circ}\right)$ and three critical frequencies $(140 \mathrm{~Hz}, 150$ $\mathrm{Hz}$, and $160 \mathrm{~Hz}$ ) will be established by using design parameters (control factors) in columns and standard rows (level) of quantities.

\section{Results and discussion}

\subsection{Results}

In order to realize the critical frequency (target frequency) that reduces the transmission efficiency of the hard disk, a hard disk without added damping material is tested using three kinds of tilted angles. The results shown in Fig. 9 indicate that the IOPS at the ranges of $120 \mathrm{~Hz} \sim 180 \mathrm{~Hz}$ is fairly low. Therefore, three target frequencies of $140 \mathrm{~Hz}, 150 \mathrm{~Hz}$, and 160 $\mathrm{Hz}$ are selected. Before establishing the ANNM and based on the Taguchi method, an orthogonal array with respect to three tilted angles $\left(0^{\circ}, 5^{\circ}\right.$, and $\left.10^{\circ}\right)$ and three critical frequencies $(140 \mathrm{~Hz}, 150 \mathrm{~Hz}$, and $160 \mathrm{~Hz})$ will be planned in advance. According the orthogonal tables, related experimental work for various combinations of damping material and tilted angles at various critical frequencies is planned.

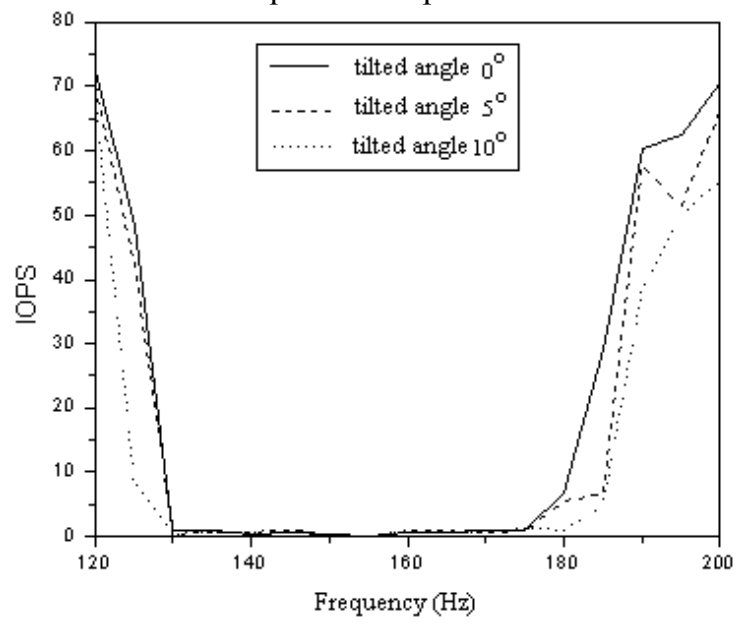

Fig. 9. The hard disk's IOPS with respect to three kinds of tilted angles without adding damping material. 


\subsubsection{IOPS at a Hard Disk's Tilted Angle of $0^{\circ}$}

Using damping material of $\mathrm{D}_{1}=\mathrm{D}_{2}=\mathrm{D}_{3}=50$, the IOPS with respect to acceleration at the target frequency of $140 \mathrm{~Hz}$ is shown in Fig. 10. Fig. 10 indicates that the IOPS has the maximum value of acceleration at $0.08(\mathrm{~g})$. Similarly, adopting damping material of $\mathrm{D}_{1}=\mathrm{D}_{2}=\mathrm{D}_{3}=50$, the IOPS with respect to acceleration at the target frequency of $150 \mathrm{~Hz}$ is shown in Fig. 11. Fig. 11 indicates that the IOPS has the maximum value of acceleration at 0.03 (g). Also, using damping material of $\mathrm{D}_{1}=\mathrm{D}_{2}=\mathrm{D}_{3}=50$, the IOPS with respect to acceleration at the target frequency of $160 \mathrm{~Hz}$ shown in Fig. 12 indicates that the IOPS has the maximum value of acceleration at $0.06(\mathrm{~g})$. Therefore, the experimental work on the transmission measurement with respect to three target frequencies $140 \mathrm{~Hz}, 150 \mathrm{~Hz}$, and 160 $\mathrm{Hz}$ under a tilted angle of $0^{\circ}$ and accelerations of $0.08,0.03$, and $0.06(\mathrm{G})$ is performed and shown in Tables 1 3.

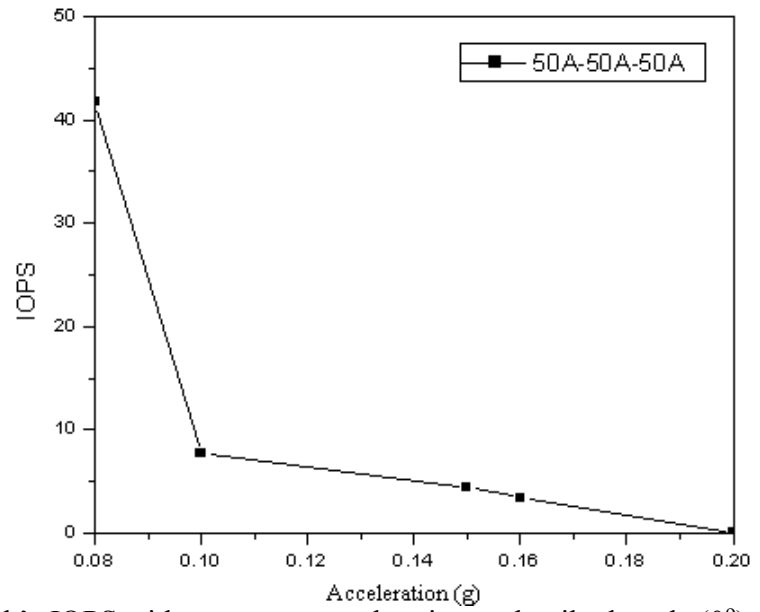

Fig. 10. The hard disk's IOPS with respect to acceleration at the tilted angle $\left(0^{\circ}\right)$ and the target frequency $(140 \mathrm{~Hz})$ using damping material $(\mathrm{D} 1=\mathrm{D} 2=\mathrm{D} 3=50)$.

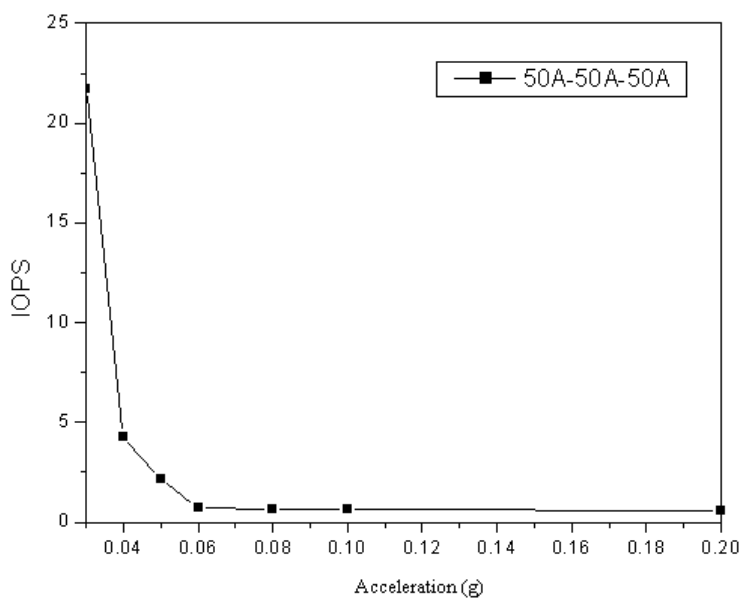

Fig. 11. The hard disk's IOPS with respect to acceleration at the tilted angle $\left(0^{\circ}\right)$ and the target frequency $(150 \mathrm{~Hz})$ using damping material $(\mathrm{D} 1=\mathrm{D} 2=\mathrm{D} 3=50)$. 


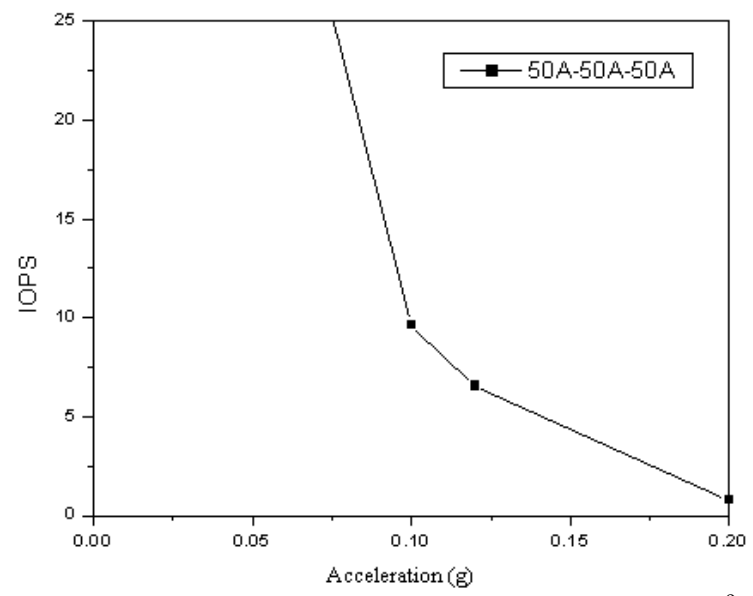

Fig. 12. The hard disk's IOPS with respect to acceleration at the tilted angle $\left(0^{\circ}\right)$ and the target frequency $(160 \mathrm{~Hz})$ using damping material $(\mathrm{D} 1=\mathrm{D} 2=\mathrm{D} 3=50)$.

Table 1. Experimental results of a hard disk with a three-layer damping material (hardness of $D_{1}, D_{2}$, and $\mathrm{D}_{3}$ ) at a tilted angle of $0^{\circ}$ and $140 \mathrm{~Hz}$.

\begin{tabular}{|c|c|c|c|c|}
\hline Item & Parameter $1\left(\mathrm{D}_{1}\right)$ & Parameter 2 $\left(\mathrm{D}_{2}\right)$ & Parameter 3 $\left(\mathrm{D}_{3}\right)$ & IOPS \\
\hline 1 & 30 & 40 & 50 & 21.97232 \\
\hline 2 & 30 & 60 & 70 & 55.29873 \\
\hline 3 & 30 & 70 & 40 & 9.57526 \\
\hline 4 & 30 & 40 & 60 & 7.86317 \\
\hline 5 & 30 & 50 & 70 & 3.30748 \\
\hline 6 & 40 & 50 & 60 & 60.14307 \\
\hline 7 & 40 & 70 & 30 & 57.00203 \\
\hline 8 & 40 & 40 & 40 & 58.85171 \\
\hline 9 & 40 & 30 & 50 & 59.83321 \\
\hline 10 & 40 & 70 & 60 & 14.17967 \\
\hline 11 & 50 & 60 & 70 & 56.15763 \\
\hline 12 & 50 & 30 & 60 & 57.31137 \\
\hline 13 & 50 & 70 & 50 & 54.46577 \\
\hline 14 & 50 & 40 & 60 & 56.48192 \\
\hline 15 & 50 & 30 & 70 & 60.81673 \\
\hline 16 & 60 & 70 & 50 & 57.26186 \\
\hline 17 & 60 & 40 & 50 & 3.23626 \\
\hline 18 & 60 & 60 & 60 & 58.67868 \\
\hline 19 & 60 & 30 & 50 & 34.40444 \\
\hline 20 & 60 & 40 & 70 & 8.46796 \\
\hline 21 & 70 & 30 & 40 & 1.70073 \\
\hline 22 & 70 & 50 & 60 & 60.57304 \\
\hline 23 & 70 & 70 & 70 & 54.00194 \\
\hline 24 & 70 & 40 & 60 & 58.30641 \\
\hline 25 & 70 & 50 & 30 & 61.19392 \\
\hline
\end{tabular}

Table 2. Experimental results of a hard disk with a three-layer damping material (hardness of $\mathrm{D}_{1}, \mathrm{D}_{2}$, and $\mathrm{D}_{3}$ ) at a tilted angle of $0^{\circ}$ and $150 \mathrm{~Hz}$.

\begin{tabular}{|c|c|c|c|c|}
\hline Item & Parameter 1 $\left(\mathrm{D}_{1}\right)$ & Parameter 2 $\left(\mathrm{D}_{2}\right)$ & Parameter 3 $\left(\mathrm{D}_{3}\right)$ & IOPS \\
\hline 1 & 30 & 40 & 50 & 4.55979 \\
\hline 2 & 30 & 60 & 70 & 18.63423 \\
\hline 3 & 30 & 70 & 40 & 2.17793 \\
\hline
\end{tabular}




\begin{tabular}{|c|c|c|c|c|}
\hline 4 & 30 & 40 & 60 & 6.44938 \\
\hline 5 & 30 & 50 & 70 & 18.16737 \\
\hline 6 & 40 & 50 & 60 & 27.91441 \\
\hline 7 & 40 & 70 & 30 & 1.60061 \\
\hline 8 & 40 & 40 & 40 & 9.94398 \\
\hline 9 & 40 & 30 & 50 & 55.45931 \\
\hline 10 & 40 & 70 & 60 & 53.85391 \\
\hline 11 & 50 & 60 & 70 & 39.70867 \\
\hline 12 & 50 & 30 & 60 & 35.34186 \\
\hline 13 & 50 & 70 & 50 & 23.01421 \\
\hline 14 & 50 & 40 & 60 & 21.13465 \\
\hline 15 & 50 & 30 & 70 & 49.11832 \\
\hline 16 & 60 & 70 & 50 & 40.18326 \\
\hline 17 & 60 & 40 & 50 & 53.69491 \\
\hline 18 & 60 & 60 & 60 & 20.15838 \\
\hline 19 & 60 & 30 & 50 & 52.57962 \\
\hline 20 & 60 & 40 & 70 & 21.34739 \\
\hline 21 & 70 & 30 & 40 & 21.94138 \\
\hline 22 & 70 & 50 & 60 & 35.19878 \\
\hline 23 & 70 & 70 & 70 & 43.44021 \\
\hline 24 & 70 & 40 & 60 & 54.94346 \\
\hline 25 & 70 & 50 & 30 & 26.09167 \\
\hline
\end{tabular}

Table 3. Experimental results of a hard disk with a three-layer damping material (hardness of $D_{1}, D_{2}$, and $\mathrm{D}_{3}$ ) at a tilted angle of $0^{\circ}$ and $160 \mathrm{~Hz}$.

\begin{tabular}{|c|c|c|c|c|}
\hline Item & Parameter $1\left(\mathrm{D}_{1}\right)$ & Parameter 2 $\left(\mathrm{D}_{2}\right)$ & Parameter $3\left(\mathrm{D}_{3}\right)$ & IOPS \\
\hline 1 & 30 & 40 & 50 & 32.46401 \\
\hline 2 & 30 & 60 & 70 & 4.35431 \\
\hline 3 & 30 & 70 & 40 & 3.74602 \\
\hline 4 & 30 & 40 & 60 & 47.84439 \\
\hline 5 & 30 & 50 & 70 & 20.38102 \\
\hline 6 & 40 & 50 & 60 & 4.89399 \\
\hline 7 & 40 & 70 & 30 & 5.44983 \\
\hline 8 & 40 & 40 & 40 & 16.99811 \\
\hline 9 & 40 & 30 & 50 & 1.85630 \\
\hline 10 & 40 & 70 & 60 & 20.50971 \\
\hline 11 & 50 & 60 & 70 & 3.38123 \\
\hline 12 & 50 & 30 & 60 & 8.46935 \\
\hline 13 & 50 & 70 & 50 & 1.01219 \\
\hline 14 & 50 & 40 & 60 & 1.56729 \\
\hline 15 & 50 & 30 & 70 & 1.42908 \\
\hline 16 & 60 & 70 & 50 & 45.36873 \\
\hline 17 & 60 & 40 & 50 & 10.61518 \\
\hline 18 & 60 & 60 & 60 & 42.03457 \\
\hline 19 & 60 & 30 & 50 & 47.61785 \\
\hline 20 & 60 & 40 & 70 & 13.42458 \\
\hline 21 & 70 & 30 & 40 & 1.83411 \\
\hline 22 & 70 & 50 & 60 & 2.34113 \\
\hline 23 & 70 & 70 & 70 & 15.12661 \\
\hline 24 & 70 & 40 & 60 & 15.65359 \\
\hline 25 & 70 & 50 & 30 & 44.52777 \\
\hline
\end{tabular}

Using the experimental data from the ANNM and applying the GA optimizer, the optimization of the combined hardness $\left(\mathrm{D}_{1}, \mathrm{D}_{2}\right.$, and $\left.\mathrm{D}_{3}\right)$ is performed. The related GA 
control parameters are shown in Table 4. The optimal results of the design parameters $\left(D_{1}=D_{2}=D_{3}=50\right)$ at the target frequencies is shown in Table 5. To meet the real hardness specifications of the damping material, real design data that is close to the optimal data are adopted. The real design data and related IOPS for three target frequencies at a tilted angle of $0^{\circ}$ are depicted in Table 6. Moreover, the original design data (without optimization) and related IOPS are illustrated in Table 7 . Comparing the transmission efficiency before and after optimization is performed, results in targeted frequencies of $140 \mathrm{~Hz}, 150 \mathrm{~Hz}$, and 160 $\mathrm{Hz}$ are plotted in Figs. 13 15.

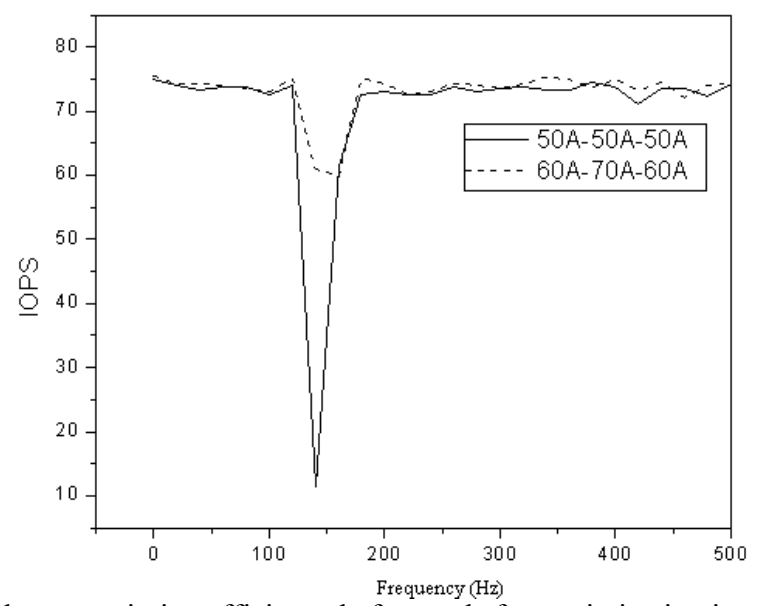

Fig. 13. Comparing the transmission efficiency before and after optimization is performed at the target frequency of $140 \mathrm{~Hz}$ (tilted angle of $0^{\circ}$ ).

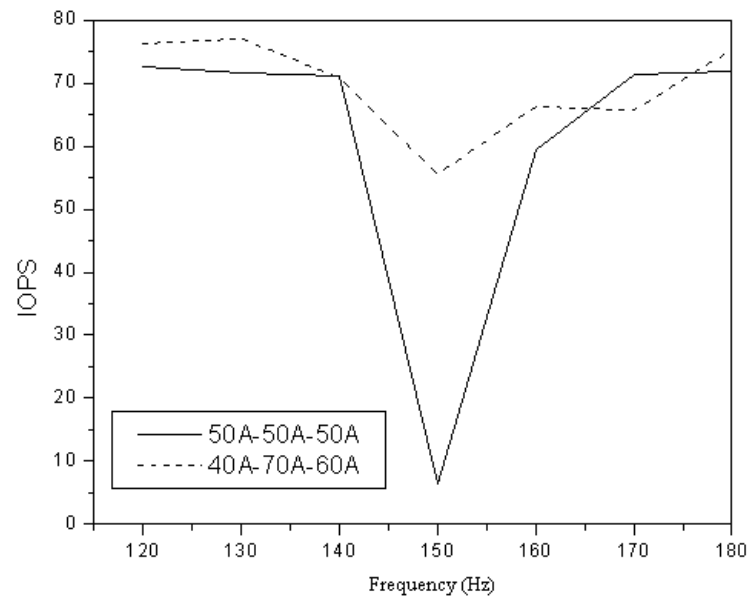

Fig. 14. Comparing the transmission efficiency before and after optimization is performed at the target frequency of $150 \mathrm{~Hz}$ (tilted angle of $0^{\circ}$ ). 


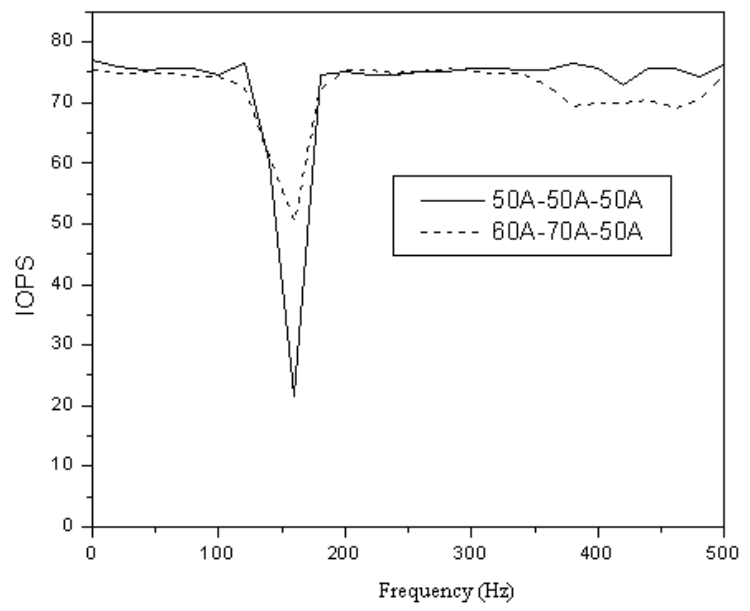

Fig. 15. Comparing the transmission efficiency before and after optimization is performed at the target frequency of $160 \mathrm{~Hz}$ (tilted angle of $0^{\circ}$ ).

Table 4. Selected GA parameters during shape optimization.

\begin{tabular}{|c|c|}
\hline GA parameters & Value (or condition) \\
\hline design variables & 3 \\
\hline chrm & 40 \\
\hline pop & 100 \\
\hline elitism & (tournament) \\
\hline crossover & (uniform crossover) \\
\hline pc & 0.8 \\
\hline pm & 0.05 \\
\hline iter $_{\max }$ & 1000 \\
\hline
\end{tabular}

Table 5. Optimal results of a hard disk with a three-layer damping material (hardness of $D_{1}, D_{2}$, and $\mathrm{D}_{3}$ ) at three target frequencies (tilted angle $=0^{\circ}$ ).

\begin{tabular}{|c|c|c|c|c|}
\hline \multirow{2}{*}{$\begin{array}{c}\text { Target frequency } \\
(\mathrm{Hz})\end{array}$} & \multicolumn{3}{|c|}{ Optimal design parameter } & OBJ \\
\cline { 2 - 5 } & Parameter 1 $\left(\mathrm{D}_{1}\right)$ & Parameter 2 $\left(\mathrm{D}_{2}\right)$ & Parameter 3 $\left(\mathrm{D}_{3}\right)$ & IOPS \\
\hline 140 & 57.5589 & 73.5525 & 62.3321 & 74.48192 \\
\hline 150 & 38.6027 & 67.3665 & 59.2364 & 64.3681 \\
\hline 160 & 57.3395 & 68.1867 & 52.0627 & 56.3769 \\
\hline
\end{tabular}

Table 6. Practical results of a hard disk with a three-layer damping material (hardness of $D_{1}, D_{2}$, and $\mathrm{D}_{3}$ ) at three target frequencies (tilted angle $=0^{\circ}$ ).

\begin{tabular}{|c|c|c|c|c|}
\hline \multirow{2}{*}{$\begin{array}{c}\text { Target frequency } \\
(\mathrm{Hz})\end{array}$} & \multicolumn{3}{|c|}{ Practical design parameter } & IOPS \\
\cline { 2 - 4 } & Parameter 1 $\left(\mathrm{D}_{1}\right)$ & Parameter 2 $\left(\mathrm{D}_{2}\right)$ & Parameter 3 $\left(\mathrm{D}_{3}\right)$ & \\
\hline 140 & 60 & 70 & 60 & 61.06 \\
\hline 150 & 40 & 70 & 60 & 55.45 \\
\hline 160 & 60 & 70 & 50 & 50.57 \\
\hline
\end{tabular}

Table 7. Original IOPS $\left(\mathrm{D}_{1}=\mathrm{D}_{2}=\mathrm{D}_{3}=50\right)$ at three target frequencies without optimization (tilted angle $=0^{\circ}$ ).

\begin{tabular}{|c|c|c|c|c|}
\hline \multirow{2}{*}{$\begin{array}{c}\text { Target frequency } \\
(\mathrm{Hz})\end{array}$} & \multicolumn{3}{|c|}{ Practical design parameter } & \multirow{2}{*}{ IOPS } \\
\cline { 2 - 4 } & Parameter $1\left(\mathrm{D}_{1}\right)$ & Parameter $2\left(\mathrm{D}_{2}\right)$ & Parameter $3\left(\mathrm{D}_{3}\right)$ & \\
\hline 140 & 50 & 50 & 50 & 11.36 \\
\hline 150 & 50 & 50 & 50 & 6.36 \\
\hline 160 & 50 & 50 & 50 & 21.43 \\
\hline
\end{tabular}




\subsubsection{IOPS at a Hard Disk's Tilted Angle of $5^{\circ}$}

Similarly, the optimization of hardness $\left(\mathrm{D}_{1}, \mathrm{D}_{2}\right.$, and $\left.\mathrm{D}_{3}\right)$ for a hard disk at a tilted angle of 5 ${ }^{\circ}$ is performed. The experimental work on the transmission measurement with respect to three target frequencies $140 \mathrm{~Hz}, 150 \mathrm{~Hz}$, and $160 \mathrm{~Hz}$ under a tilted angle of $5^{\circ}$ and accelerations of $0.08,0.03$, and $0.06(\mathrm{G})$ is performed and shown in Tables $8 \sim 10$. Using the experimental data from the ANNM and applying the GA optimizer, the optimal design parameters $\left(D_{1}=D_{2}=D_{3}=50\right)$ at the target frequencies is shown in Table 11 . To meet the real hardness specification for the damping material, real design data that is close to the optimal data is adopted. The real design data and related IOPS for three target frequencies at a tilted angle of $5^{\circ}$ are depicted in Table 12. Moreover, the original design data (without optimization) and related IOPS are illustrated in Table 13. Comparing the transmission efficiency before and after optimization is performed, results in targeted frequencies of 140 $\mathrm{Hz}, 150 \mathrm{~Hz}$, and $160 \mathrm{~Hz}$ are plotted in Figs. 16 18.

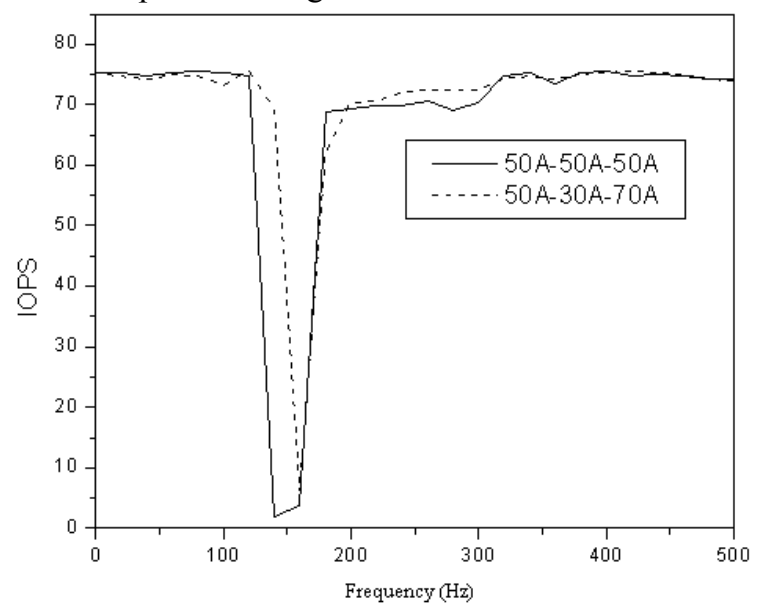

Fig. 16. Comparing the transmission efficiency before and after optimization is performed at the target frequency of $140 \mathrm{~Hz}$ (tilted angle of $5^{\circ}$ ).

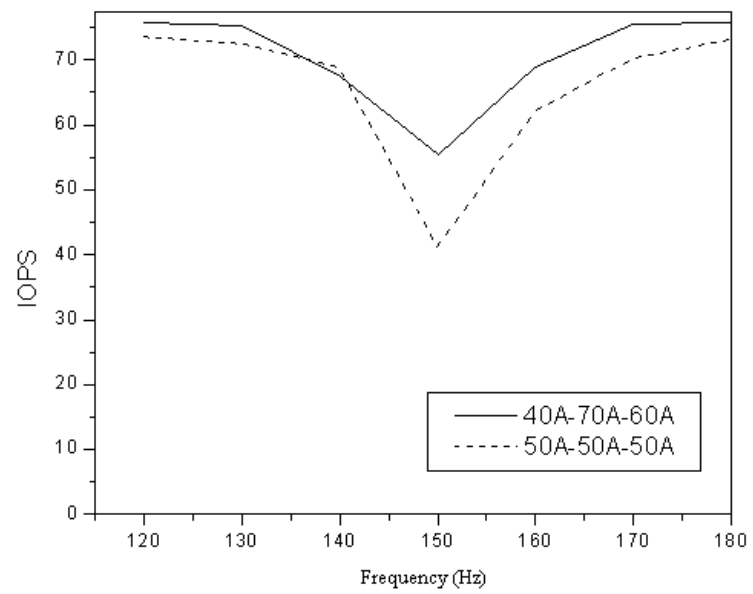

Fig. 17. Comparing the transmission efficiency before and after optimization is performed at the target frequency of $150 \mathrm{~Hz}$ (tilted angle of $5^{\circ}$ ). 


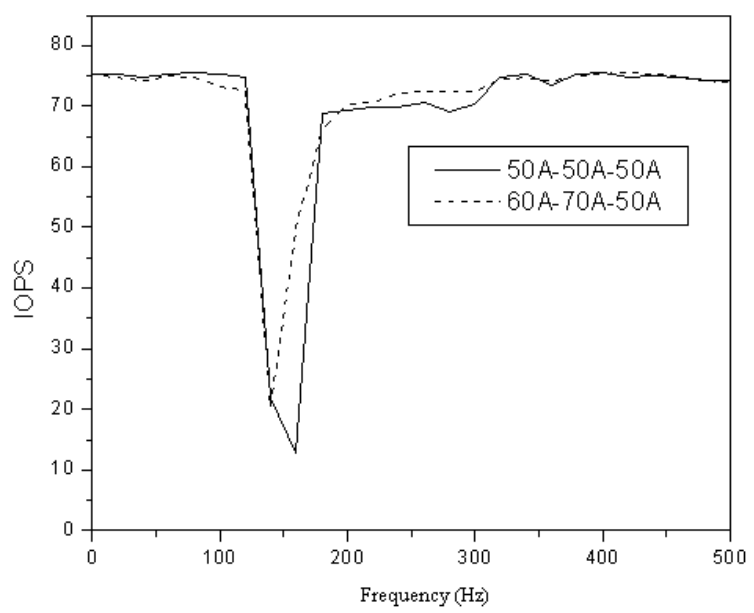

Fig. 18. Comparing the transmission efficiency before and after optimization is performed at the target frequency of $160 \mathrm{~Hz}$ (tilted angle of $5^{\circ}$ ).

Table 8. Experimental results of a hard disk with a three-layer damping material (hardness of $D_{1}, D_{2}$, and $\mathrm{D}_{3}$ ) at a tilted angle of $5^{\circ}$ and $140 \mathrm{~Hz}$.

\begin{tabular}{|c|c|c|c|c|}
\hline Item & Parameter $1\left(\mathrm{D}_{1}\right)$ & Parameter $2\left(\mathrm{D}_{2}\right)$ & Parameter 3 $\left(\mathrm{D}_{3}\right)$ & IOPS \\
\hline 1 & 30 & 40 & 50 & 3.09138 \\
\hline 2 & 30 & 60 & 70 & 46.66624 \\
\hline 3 & 30 & 70 & 40 & 8.46956 \\
\hline 4 & 30 & 40 & 60 & 17.57293 \\
\hline 5 & 30 & 50 & 70 & 8.92974 \\
\hline 6 & 40 & 50 & 60 & 15.87552 \\
\hline 7 & 40 & 70 & 30 & 58.84662 \\
\hline 8 & 40 & 40 & 40 & 53.74312 \\
\hline 9 & 40 & 30 & 50 & 27.87799 \\
\hline 10 & 40 & 70 & 60 & 11.23359 \\
\hline 11 & 50 & 60 & 70 & 65.64529 \\
\hline 12 & 50 & 30 & 60 & 33.51206 \\
\hline 13 & 50 & 70 & 50 & 59.55521 \\
\hline 14 & 50 & 40 & 60 & 64.06865 \\
\hline 15 & 50 & 30 & 70 & 65.92546 \\
\hline 16 & 60 & 70 & 50 & 63.33052 \\
\hline 17 & 60 & 40 & 50 & 3.85896 \\
\hline 18 & 60 & 60 & 60 & 56.78851 \\
\hline 19 & 60 & 30 & 50 & 33.13341 \\
\hline 20 & 60 & 40 & 70 & 1.08436 \\
\hline 21 & 70 & 30 & 40 & 1.08953 \\
\hline 22 & 70 & 50 & 60 & 11.36135 \\
\hline 23 & 70 & 70 & 70 & 59.00901 \\
\hline 24 & 70 & 40 & 60 & 60.67589 \\
\hline 25 & 70 & 50 & 30 & 52.10223 \\
\hline
\end{tabular}

Table 9. Experimental results of a hard disk with a three-layer damping material (hardness of $D_{1}, D_{2}$, and $\mathrm{D}_{3}$ ) at a tilted angle of $5^{\circ}$ and $150 \mathrm{~Hz}$.

\begin{tabular}{|c|c|c|c|c|}
\hline Item & Parameter 1 $\left(\mathrm{D}_{1}\right)$ & Parameter 2 $\left(\mathrm{D}_{2}\right)$ & Parameter 3 $\left(\mathrm{D}_{3}\right)$ & IOPS \\
\hline 1 & 30 & 40 & 50 & 47.52115 \\
\hline 2 & 30 & 60 & 70 & 32.82668 \\
\hline 3 & 30 & 70 & 40 & 6.44015 \\
\hline
\end{tabular}




\begin{tabular}{|c|c|c|c|c|}
\hline 4 & 30 & 40 & 60 & 4.52681 \\
\hline 5 & 30 & 50 & 70 & 26.76372 \\
\hline 6 & 40 & 50 & 60 & 5.16036 \\
\hline 7 & 40 & 70 & 30 & 8.50283 \\
\hline 8 & 40 & 40 & 40 & 22.62648 \\
\hline 9 & 40 & 30 & 50 & 33.25664 \\
\hline 10 & 40 & 70 & 60 & 66.28423 \\
\hline 11 & 50 & 60 & 70 & 20.91662 \\
\hline 12 & 50 & 30 & 60 & 28.80622 \\
\hline 13 & 50 & 70 & 50 & 4.21008 \\
\hline 14 & 50 & 40 & 60 & 22.10794 \\
\hline 15 & 50 & 30 & 70 & 5.63342 \\
\hline 16 & 60 & 70 & 50 & 13.67966 \\
\hline 17 & 60 & 40 & 50 & 51.90243 \\
\hline 18 & 60 & 60 & 60 & 44.63756 \\
\hline 19 & 60 & 30 & 50 & 55.86545 \\
\hline 20 & 60 & 40 & 70 & 48.08131 \\
\hline 21 & 70 & 30 & 40 & 24.77616 \\
\hline 22 & 70 & 50 & 60 & 8.86914 \\
\hline 23 & 70 & 70 & 70 & 13.55824 \\
\hline 24 & 70 & 40 & 60 & 24.37131 \\
\hline 25 & 70 & 50 & 30 & 38.42977 \\
\hline
\end{tabular}

Table 10. Experimental results of a hard disk with a three-layer damping material (hardness of $D_{1}$, $\mathrm{D}_{2}$, and $\mathrm{D}_{3}$ ) at a tilted angle of $5^{\circ}$ and $160 \mathrm{~Hz}$.

\begin{tabular}{|c|c|c|c|c|}
\hline Item & Parameter $1\left(\mathrm{D}_{1}\right)$ & Parameter 2 $\left(\mathrm{D}_{2}\right)$ & Parameter 3 $\left(\mathrm{D}_{3}\right)$ & IOPS \\
\hline 1 & 30 & 40 & 50 & 27.22337 \\
\hline 2 & 30 & 60 & 70 & 5.98962 \\
\hline 3 & 30 & 70 & 40 & 2.66482 \\
\hline 4 & 30 & 40 & 60 & 19.90615 \\
\hline 5 & 30 & 50 & 70 & 9.59281 \\
\hline 6 & 40 & 50 & 60 & 6.80697 \\
\hline 7 & 40 & 70 & 30 & 1.56727 \\
\hline 8 & 40 & 40 & 40 & 3.11403 \\
\hline 9 & 40 & 30 & 50 & 2.17442 \\
\hline 10 & 40 & 70 & 60 & 23.17627 \\
\hline 11 & 50 & 60 & 70 & 17.51487 \\
\hline 12 & 50 & 30 & 60 & 7.00062 \\
\hline 13 & 50 & 70 & 50 & 1.10011 \\
\hline 14 & 50 & 40 & 60 & 1.81187 \\
\hline 15 & 50 & 30 & 70 & 2.81924 \\
\hline 16 & 60 & 70 & 50 & 50.95341 \\
\hline 17 & 60 & 40 & 50 & 17.82112 \\
\hline 18 & 60 & 60 & 60 & 40.61928 \\
\hline 19 & 60 & 30 & 50 & 44.27424 \\
\hline 20 & 60 & 40 & 70 & 10.56677 \\
\hline 21 & 70 & 30 & 40 & 1.82861 \\
\hline 22 & 70 & 50 & 60 & 1.70727 \\
\hline 23 & 70 & 70 & 70 & 47.45103 \\
\hline 24 & 70 & 40 & 60 & 23.71135 \\
\hline 25 & 70 & 50 & 30 & 21.09823 \\
\hline
\end{tabular}


Table 11. Optimal result of a hard disk with a three-layer damping material (hardness of $D_{1}, D_{2}$, and $\mathrm{D}_{3}$ ) at three target frequencies (tilted angle $=5^{\circ}$ ).

\begin{tabular}{|c|c|c|c|c|}
\hline \multirow{2}{*}{$\begin{array}{c}\text { Target frequency } \\
(\mathrm{Hz})\end{array}$} & \multicolumn{3}{|c|}{ Optimal design parameter } & OBJ \\
\cline { 2 - 5 } & Parameter 1 $\left(\mathrm{D}_{1}\right)$ & Parameter 2 $\left(\mathrm{D}_{2}\right)$ & Parameter 3 $\left(\mathrm{D}_{3}\right)$ & IOPS \\
\hline 140 & 47.2256 & 33.4489 & 66.3825 & 72.8632 \\
\hline 150 & 42.8749 & 70.3235 & 61.8612 & 57.3342 \\
\hline 160 & 62.0962 & 70.9005 & 45.3971 & 64.8916 \\
\hline
\end{tabular}

Table 12. Practical results of a hard disk with a three-layer damping material (hardness of $D_{1}, D_{2}$, and $\mathrm{D}_{3}$ ) at three target frequencies (tilted angle $=5^{\circ}$ ).

\begin{tabular}{|c|c|c|c|c|}
\hline \multirow{2}{*}{$\begin{array}{c}\text { Target frequency } \\
(\mathrm{Hz})\end{array}$} & \multicolumn{3}{|c|}{ Practical design parameter } & IOPS \\
\cline { 2 - 4 } & Parameter 1 $\left(\mathrm{D}_{1}\right)$ & Parameter 2 $\left(\mathrm{D}_{2}\right)$ & Parameter 3 $\left(\mathrm{D}_{3}\right)$ & \\
\hline 140 & 50 & 30 & 70 & 66.22 \\
\hline 150 & 40 & 70 & 60 & 55.36 \\
\hline 160 & 60 & 70 & 50 & 50.02 \\
\hline
\end{tabular}

Table 13. Original IOPS $\left(D_{1}=D_{2}=D_{3}=50\right)$ at three target frequencies without optimization (tilted angle $=5^{\circ}$ ).

\begin{tabular}{|c|c|c|c|c|}
\hline $\begin{array}{c}\text { Target frequency } \\
(\mathrm{Hz})\end{array}$ & \multicolumn{3}{|c|}{ Practical design parameter } & IOPS \\
\cline { 2 - 4 } & Parameter 1 $\left(\mathrm{D}_{1}\right)$ & Parameter 2 $\left(\mathrm{D}_{2}\right)$ & Parameter 3 $\left(\mathrm{D}_{3}\right)$ & \\
\hline 140 & 50 & 50 & 50 & 6.43 \\
\hline 150 & 50 & 50 & 50 & 41.24 \\
\hline 160 & 50 & 50 & 50 & 12.12 \\
\hline
\end{tabular}

\subsubsection{IOPS at a Hard Disk's Tilted Angle of $10^{\circ}$}

Equally, the optimization of hardness $\left(D_{1}, D_{2}\right.$, and $\left.D_{3}\right)$ for a hard disk at a tilted angle of 10 ${ }^{\circ}$ is performed. The experimental work for the transmission measurement with respect to three target frequencies $140 \mathrm{~Hz}, 150 \mathrm{~Hz}$, and $160 \mathrm{~Hz}$ under a tilted angle of $10^{\circ}$ and accelerations of $0.08,0.03$, and $0.06(\mathrm{G})$ is performed and shown in Tables 14 16. Using the experimental data from the ANNM and applying the GA optimizer, the optimal design parameters $\left(D_{1}=D_{2}=D_{3}=50\right)$ at the target frequencies are shown in Table 17. To meet real hardness specifications for the damping material, real design data that is close to the optimal data is adopted. The real design data and related IOPS for the three target frequencies at a tilted angle of $10^{\circ}$ are depicted in Table 18. Moreover, the original design data (without optimization) and related IOPS are illustrated in Table 19. Comparing the transmission efficiency before and after optimization is performed, results in frequencies of $140 \mathrm{~Hz}, 150 \mathrm{~Hz}$, and $160 \mathrm{~Hz}$ are plotted in Figs. 19 21.

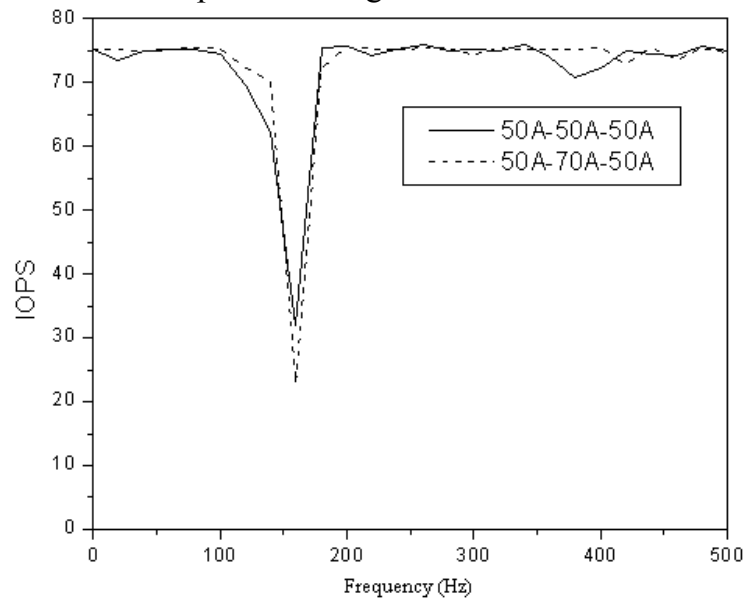

Fig. 19. Comparing the transmission efficiency before and after optimization is performed at the target frequency of $140 \mathrm{~Hz}$ (tilted angle of $10^{\circ}$ ). 


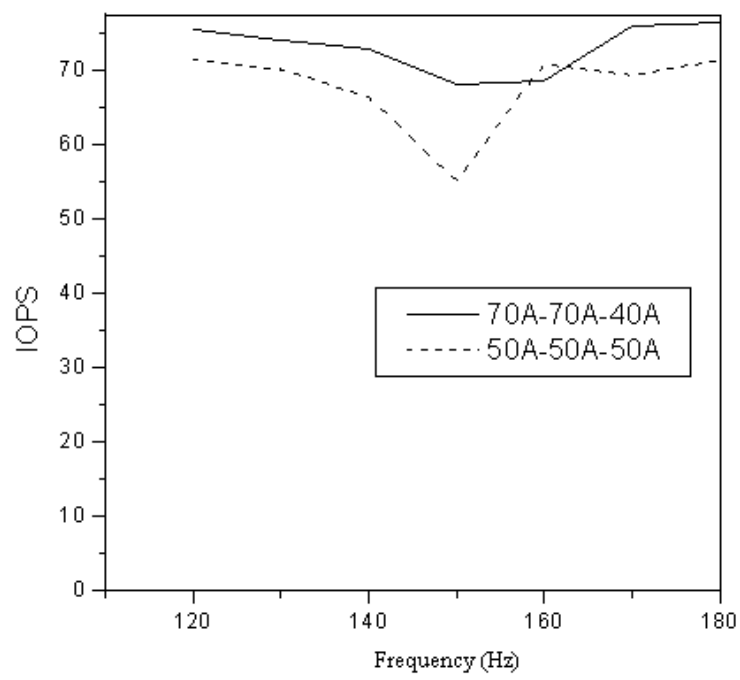

Fig. 20. Comparing the transmission efficiency before and after optimization is performed at the target frequency of $150 \mathrm{~Hz}$ (tilted angle of $10^{\circ}$ ).

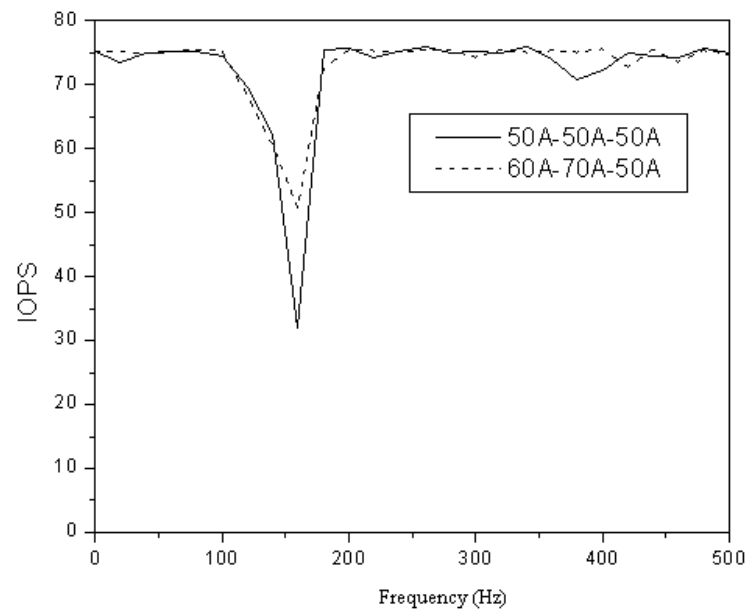

Fig. 21. Comparing the transmission efficiency before and after optimization is performed at the target frequency of $160 \mathrm{~Hz}$ (tilted angle of $10^{\circ}$ ).

Table 14. Experimental results of a hard disk with a three-layer damping material (hardness of $D_{1}, D_{2}$, and $\mathrm{D}_{3}$ ) at a tilted angle of $10^{\circ}$ and $140 \mathrm{~Hz}$.

\begin{tabular}{|c|c|c|c|c|}
\hline Item & Parameter $1\left(\mathrm{D}_{1}\right)$ & Parameter 2 $\left(\mathrm{D}_{2}\right)$ & Parameter 3 $\left(\mathrm{D}_{3}\right)$ & IOPS \\
\hline 1 & 30 & 40 & 50 & 1.80081 \\
\hline 2 & 30 & 60 & 70 & 48.68469 \\
\hline 3 & 30 & 70 & 40 & 13.81347 \\
\hline 4 & 30 & 40 & 60 & 3.19666 \\
\hline 5 & 30 & 50 & 70 & 3.00747 \\
\hline 6 & 40 & 50 & 60 & 3.30326 \\
\hline 7 & 40 & 70 & 30 & 65.93559 \\
\hline 8 & 40 & 40 & 40 & 29.20518 \\
\hline 9 & 40 & 30 & 50 & 53.84428 \\
\hline 10 & 40 & 70 & 60 & 10.00949 \\
\hline
\end{tabular}




\begin{tabular}{|l|l|l|l|l|}
\hline 11 & 50 & 60 & 70 & 65.52351 \\
\hline 12 & 50 & 30 & 60 & 10.81129 \\
\hline 13 & 50 & 70 & 50 & 66.19763 \\
\hline 14 & 50 & 40 & 60 & 39.31431 \\
\hline 15 & 50 & 30 & 70 & 40.71456 \\
\hline 16 & 60 & 70 & 50 & 55.72275 \\
\hline 17 & 60 & 40 & 50 & 57.18641 \\
\hline 18 & 60 & 60 & 60 & 54.34626 \\
\hline 19 & 60 & 30 & 50 & 44.93873 \\
\hline 20 & 60 & 40 & 70 & 3.17489 \\
\hline 21 & 70 & 30 & 40 & 1.68952 \\
\hline 22 & 70 & 50 & 60 & 59.49621 \\
\hline 23 & 70 & 70 & 70 & 47.39454 \\
\hline 24 & 70 & 40 & 60 & 53.81705 \\
\hline 25 & 70 & 50 & 30 & 46.89436 \\
\hline
\end{tabular}

Table 15. Experimental results of a hard disk with a three-layer damping material (hardness of $D_{1}, D_{2}$, and $\mathrm{D}_{3}$ ) at a tilted angle of $10^{\circ}$ and $150 \mathrm{~Hz}$.

\begin{tabular}{|c|c|c|c|c|}
\hline Item & Parameter $1\left(\mathrm{D}_{1}\right)$ & Parameter $2\left(\mathrm{D}_{2}\right)$ & Parameter 3 $\left(\mathrm{D}_{3}\right)$ & IOPS \\
\hline 1 & 30 & 40 & 50 & 45.32489 \\
\hline 2 & 30 & 60 & 70 & 40.98301 \\
\hline 3 & 30 & 70 & 40 & 2.81179 \\
\hline 4 & 30 & 40 & 60 & 8.98616 \\
\hline 5 & 30 & 50 & 70 & 17.39083 \\
\hline 6 & 40 & 50 & 60 & 43.29303 \\
\hline 7 & 40 & 70 & 30 & 8.76413 \\
\hline 8 & 40 & 40 & 40 & 12.17231 \\
\hline 9 & 40 & 30 & 50 & 44.13115 \\
\hline 10 & 40 & 70 & 60 & 56.33476 \\
\hline 11 & 50 & 60 & 70 & 28.36053 \\
\hline 12 & 50 & 30 & 60 & 41.23089 \\
\hline 13 & 50 & 70 & 50 & 4.53785 \\
\hline 14 & 50 & 40 & 60 & 7.09557 \\
\hline 15 & 50 & 30 & 70 & 21.23833 \\
\hline 16 & 60 & 70 & 50 & 56.01829 \\
\hline 17 & 60 & 40 & 50 & 50.85596 \\
\hline 18 & 60 & 60 & 60 & 34.41528 \\
\hline 19 & 60 & 30 & 50 & 52.28129 \\
\hline 20 & 60 & 40 & 70 & 15.39809 \\
\hline 21 & 70 & 30 & 40 & 60.10214 \\
\hline 22 & 70 & 50 & 60 & 26.79049 \\
\hline 23 & 70 & 70 & 70 & 21.32682 \\
\hline 24 & 70 & 40 & 60 & 48.12752 \\
\hline 25 & 70 & 50 & 30 & 29.67769 \\
\hline
\end{tabular}

Table 16. Experimental results of a hard disk with a three-layer damping material (hardness of $D_{1}, D_{2}$, and $\mathrm{D}_{3}$ ) at a tilted angle of $10^{\circ}$ and $160 \mathrm{~Hz}$.

\begin{tabular}{|c|c|c|c|c|}
\hline Item & Parameter $1\left(\mathrm{D}_{1}\right)$ & Parameter $2\left(\mathrm{D}_{2}\right)$ & Parameter 3 $\left(\mathrm{D}_{3}\right)$ & IOPS \\
\hline 1 & 30 & 40 & 50 & 25.32489 \\
\hline 2 & 30 & 60 & 70 & 2.57491 \\
\hline 3 & 30 & 70 & 40 & 3.11967 \\
\hline 4 & 30 & 40 & 60 & 27.58612 \\
\hline 5 & 30 & 50 & 70 & 13.67468 \\
\hline 6 & 40 & 50 & 60 & 11.70491 \\
\hline 7 & 40 & 70 & 30 & 1.55053 \\
\hline
\end{tabular}




\begin{tabular}{|c|c|c|c|c|}
\hline 8 & 40 & 40 & 40 & 3.84822 \\
\hline 9 & 40 & 30 & 50 & 1.73401 \\
\hline 10 & 40 & 70 & 60 & 3.99291 \\
\hline 11 & 50 & 60 & 70 & 5.18783 \\
\hline 12 & 50 & 30 & 60 & 7.23593 \\
\hline 13 & 50 & 70 & 50 & 1.86749 \\
\hline 14 & 50 & 40 & 60 & 1.71731 \\
\hline 15 & 50 & 30 & 70 & 1.83482 \\
\hline 16 & 60 & 70 & 50 & 47.65246 \\
\hline 17 & 60 & 40 & 50 & 22.72884 \\
\hline 18 & 60 & 60 & 60 & 49.75337 \\
\hline 19 & 60 & 30 & 50 & 40.21922 \\
\hline 20 & 60 & 40 & 70 & 12.46766 \\
\hline 21 & 70 & 30 & 40 & 1.41149 \\
\hline 22 & 70 & 50 & 60 & 1.38483 \\
\hline 23 & 70 & 70 & 70 & 49.78942 \\
\hline 24 & 70 & 40 & 60 & 4.23209 \\
\hline 25 & 70 & 50 & 30 & 37.41532 \\
\hline
\end{tabular}

Table 17. Optimal result of a hard disk with a three-layer damping material (hardness of $D_{1}, D_{2}$, and $\mathrm{D}_{3}$ ) at three target frequencies (tilted angle $=10^{\circ}$ ).

\begin{tabular}{|c|c|c|c|c|}
\hline \multirow{2}{*}{$\begin{array}{c}\text { Target frequency } \\
(\mathrm{Hz})\end{array}$} & \multicolumn{3}{|c|}{ Optimal design parameter } & OBJ \\
\cline { 2 - 5 } & Parameter 1 $\left(\mathrm{D}_{1}\right)$ & Parameter 2 $\left(\mathrm{D}_{2}\right)$ & Parameter 3 $\left(\mathrm{D}_{3}\right)$ & IOPS \\
\hline 140 & 46.3258 & 71.0052 & 54.6587 & 70.3894 \\
\hline 150 & 72.2311 & 67.5274 & 41.5288 & 67.2318 \\
\hline 160 & 56.1108 & 73.5341 & 54.2323 & 59.5564 \\
\hline
\end{tabular}

Table 18. Practical result of a hard disk with a three-layer damping material (hardness of $D_{1}, D_{2}$, and $\mathrm{D}_{3}$ ) at three target frequencies (tilted angle $=10^{\circ}$ ).

\begin{tabular}{|c|c|c|c|c|}
\hline $\begin{array}{c}\text { Target frequency } \\
(\mathrm{Hz})\end{array}$ & \multicolumn{3}{|c|}{ Practical design parameter } & IOPS \\
\cline { 2 - 4 } & Parameter $1\left(\mathrm{D}_{1}\right)$ & Parameter 2 $\left(\mathrm{D}_{2}\right)$ & Parameter $3\left(\mathrm{D}_{3}\right)$ & \\
\hline 140 & 50 & 70 & 50 & 70.14 \\
\hline 150 & 70 & 70 & 40 & 68.11 \\
\hline 160 & 60 & 70 & 50 & 50.85 \\
\hline
\end{tabular}

Table 19. Original IOPS $\left(D_{1}=D_{2}=D_{3}=50\right)$ at three target frequencies without optimization (tilted angle $=10^{\circ}$ ).

\begin{tabular}{|c|c|c|c|c|}
\hline \multirow{2}{*}{$\begin{array}{c}\text { Target frequency } \\
(\mathrm{Hz})\end{array}$} & \multicolumn{3}{|c|}{ Practical design parameter } & \multirow{2}{*}{ IOPS } \\
\cline { 2 - 4 } & Parameter $1\left(\mathrm{D}_{1}\right)$ & Parameter 2 $\left(\mathrm{D}_{2}\right)$ & Parameter 3 $\left(\mathrm{D}_{3}\right)$ & \\
\hline 140 & 50 & 50 & 50 & 62.14 \\
\hline 150 & 50 & 50 & 50 & 55.16 \\
\hline 160 & 50 & 50 & 50 & 32.03 \\
\hline
\end{tabular}

\subsection{Discussion}

As deduced in Eq.(5), in case of $\omega^{2}<<\omega_{n}^{2}, Z(\omega)$, the displacement of the disk, is simplified as

$Z(\omega)=Y r^{2}$

If the frequency is $\omega^{2}>>\omega_{n}^{2}, Z(\omega)$ will become

$Z(\omega)=Y$

Whereas, in case of $\omega^{2}=\omega_{n}^{2}$ (resonance), $Z(\omega)$ yields 


$$
\begin{aligned}
& Z(\omega)=\frac{Y}{2 \varsigma_{s y s}} \\
& =\frac{\sqrt{\left(\frac{k_{1} \cdot k_{2} \cdot k_{3}}{k_{1} \cdot k_{2}+k_{1} \cdot k_{3}+k_{2} \cdot k_{3}}\right) m \cdot Y}}{\frac{c_{1} \cdot c_{2} \cdot c_{3}}{c_{1} \cdot c_{2}+c_{1} \cdot c_{3}+c_{2} \cdot c_{3}}} \\
& \overline{c_{1} \cdot c_{2}+c_{1} \cdot c_{3}+c_{2} \cdot c_{3}} \\
& =\frac{\sqrt{\left(\frac{f_{12}\left(D_{1}\right) \cdot f_{22}\left(D_{2}\right) \cdot f_{32}\left(D_{3}\right)}{f_{11}\left(D_{1}\right) \cdot f_{21}\left(D_{2}\right)+f_{11}\left(D_{1}\right) \cdot f_{31}\left(D_{3}\right)+f_{21}\left(D_{2}\right) \cdot f_{31}\left(D_{3}\right)}\right)} m \cdot Y}{\frac{f_{11}\left(D_{1}\right) \cdot f_{21}\left(D_{2}\right) \cdot f_{31}\left(D_{3}\right)}{f_{11}\left(D_{1}\right) \cdot f_{21}\left(D_{2}\right)+f_{11}\left(D_{1}\right) \cdot f_{31}\left(D_{3}\right)+f_{21}\left(D_{2}\right) \cdot f_{31}\left(D_{3}\right)}}
\end{aligned}
$$

As mentioned in Eqs.(13) (15), for a tilted angle of $0^{\circ}$, the displacement of the hard disk induced by the external based-excitation vibration is tightly related to the forcing based-excitation frequency, the system's natural frequency, the amplitude of the baseexcitation (Y), and the hardness combination of three damping material. Here, the amplitude of the base-excitation (Y) is related to the base acceleration. If it is in the case of the resonant condition (for a specified bas-excitation motion), the displacement of the hard disk will decrease when the system's damping ratio increases. Also, the transmission efficiency will be improved if the induced displacement of the hard disk is small. Therefore, the finding of a best combination for three damping material is essential. Moreover, for a tilted angle with non-zero degree, because of the unbalance force installed on the spring/damping system, the induced displacement of the hard disk will be expected to increase.

As indicated in Fig. 4, the transmission efficiency at the ranges of $120 \mathrm{~Hz} \sim 180 \mathrm{~Hz}$ is very low. Therefore, the three target frequencies of $140 \mathrm{~Hz}, 150 \mathrm{~Hz}$, and $160 \mathrm{~Hz}$ are selected and used in the hardness optimization for the three-layer damping material. As indicated in Tables $6 \sim 7$, for a hard disk vibrating at a tilted angle of $0^{\circ}$ and accelerating at $0.08(\mathrm{G})$, the transmission efficiency (IOPS) will be improved from 11.36 to 61.06 at $140 \mathrm{~Hz}$ using the hardness combination of $(60,70,60)$. In addition, the transmission efficiency (IOPS) will be enhanced from 6.36 to 55.45 at $150 \mathrm{~Hz}$ using the hardness combination of 40, 70, and 60 . Also, the transmission efficiency (IOPS) will increase from 21.43 to 50.57 at $160 \mathrm{~Hz}$ using the hardness combination of 60,70 , and 50. Additionally, as indicated in Tables 12 13, for a hard disk vibrating at a tilted angle of $5^{\circ}$ and accelerating at $0.03(\mathrm{G})$, the transmission efficiency (IOPS) will be improved from 6.43 to 66.22 at $140 \mathrm{~Hz}$ when using the hardness combination of 50,30, and 70. Also, the transmission efficiency (IOPS) will be enhanced from 41.24 to 55.36 at $150 \mathrm{~Hz}$ when using the hardness combination of 40, 70, and 60. In addition, the transmission efficiency (IOPS) will increase from 12.12 to 50.02 at $160 \mathrm{~Hz}$ using the hardness combination of 60,70, and 50. Moreover, as indicated in Tables 18 19, for a hard disk vibrating at a tilted angle of $10^{\circ}$ and accelerating at $0.06(\mathrm{G})$, the transmission efficiency (IOPS) will be improved from 62.14 to 70.14 at $140 \mathrm{~Hz}$ when the hardness combination is 50,70 , and 50 . Also, the transmission efficiency (IOPS) will be enhanced from 55.16 to 68.11 at $150 \mathrm{~Hz}$ when the hardness combination is 70, 70, and 40 . Consequently, the transmission efficiency (IOPS) will increase from 32.03 to 50.85 at 160 $\mathrm{Hz}$ when the hardness combination is 60,70 , and 50 . 


\section{Conclusions}

As can be seen in Eqs.(13) (15), the induced displacement of the hard disk is closely related to the forcing based-excitation frequency, the system's natural frequency, the acceleration (Y), and the hardness combination of three damping material. Also, the tilted angle with unbalanced force will largely influence the hard disk's motion. In order to depress the vibration effect to the hard disk's data transmission, a best combination for three damping material, an appropriate base acceleration, and a fitful tilted angle are necessary.

Experimental work shown in Fig. 4 indicates that the transmission efficiency at the ranges of $120 \mathrm{~Hz} \sim 180 \mathrm{~Hz}$ is very low when using the acceleration of base-excitation at 0.2 (G). To reduce the vibrational impact on data transmission efficiency, a three-layer damping material installed under the hard disk is adopted. An assessment of the damping material's hardness $\left(\mathrm{D}_{1}, \mathrm{D}_{2}\right.$, and $\left.\mathrm{D}_{3}\right)$ is performed by using the Artificial Neural Network Model (ANNM) and the GA Method. Before the optimization of the damping material is performed, the required experimental sets for data transmission testing will be determined by using the Taguchi method. Here, the ANNM, a simplified objective function (OBJ), is established by inputting the hardness $\left(\mathrm{D}_{1}, \mathrm{D}_{2}\right.$, and $\left.\mathrm{D}_{3}\right)$ of three layers of damping material and their related data transmission efficiency (IOPS) at a targeted transmission frequency. Results reveal that the transmission efficiency of a hard disk at three tilted angles can be efficiently improved at targeted frequencies within a base-excitation vibrating environment using the GA optimization. For a hard disk with a tilted angle of $0^{\circ}$, the increments of IOPS at the target frequencies $(140 \mathrm{~Hz}, 150 \mathrm{~Hz}, 160 \mathrm{~Hz})$ are 49.7, 49.09, and 29.14. In addition, for a hard disk tilted at $5^{\circ}$, the increments of IOPS with respect to the target frequencies $(140 \mathrm{~Hz}, 150 \mathrm{~Hz}, 160 \mathrm{~Hz})$ are $50.79,14.12$, and 37.9. Also, for a hard disk tilted at $10^{\circ}$, the increments of IOPS with respect to the target frequencies $(140 \mathrm{~Hz}, 150 \mathrm{~Hz}, 160 \mathrm{~Hz})$ are 8.0 , 12.95 , and 18.82 .

Consequently, the assessment of the three-layer damping material's hardness using the Taguchi method, the GA optimization, as well as the ANN's model is quite efficient.

\section{References}

1. J. Van der Geer, J.A. J. Hanraads, R.A. Lupton, The art of writing a scientific article. Journal of Scientific Communications, 163, 51-59 (2000)

2. C.C. Chang, Optimum isolation design for enhancing transmission efficiency of a hard disk drive, Master Thesis, Tatung University, Taiwan (2011)

3. J.C. Chang, The application of Taguchi method in the finite element analysis for the optimal structural design of compressed sheet in huge extended plate, Master Thesis, National Chung Hsing University, Taiwan (2000)

4. H.M. Chen, Shape optimization of rubber dome of key shell fragment using polynomial network and genetic algorithm, the 23th Chinese Society of Mechanical Engineer, 129-135 (2006)

5. W.J. Chiou, S.C. Huang, Modeling and vibration simulation of a spinning PC hard disk, Proceedings of the 10th National Conference of the CSME, 667-677 (1993)

6. J.H. Holland, Adaptation in natural and artificial system, Ann Arbor, MI, The University of Michigan Press (1975)

7. A.G. Ivakhnenko, Polynomial theory of complex system, IEEE Trans. Syst. Man. Cyber., 1(4), 364-368 (1971)

8. D. Jong, Analysis of the behavior of a class of genetic adaptive systems, $\mathrm{PhD}$ Dissertation, The University of Michigan Press (1975) 
9. T.S. Lan, M.C. Chiu, L.J. Yeh, An approach to rib design of injection molded project using finite element and Taguchi method, Information Technology Journal, 7(2), 299305, (2008)

10. H.H. Li, Taguchi method-theory and experiment on quality design, Gau-Li, Taipei, (2000)

11. A. Patrikar, J. Provence, Nonlinear system identification and adaptive control using polynomial networks, Math. Comput. Modeling, 123(1/2), 159-173 (1996)

12. S.J. Shiu, Transmission rate enhancement of disk drive system subjected to base excitation at different inclined angles, Master Thesis, Tatung University, Taiwan (2008)

13. C.C. Tai, Y.L. Chi, The influence of processing parameters on the flatness for a contact surface of plastic connectors, Journal of Advanced Engineering, 3(2) (2008)

14. M.S. Tsai, W.H. Yuan, J.M. Chang, Active vibration control of hard-disk drives using PZT actuated suspension systems, The 13th International Congress on Sound and Vibration, Cairns, Australia (2007)

15. H.S. Wei, Analysis for the optimum conditions in derrick hook by using Taguchi method, Master Thesis, National Ping Tung University of Science and Technology, Taiwan (2002) 